\title{
(2) OPEN ACCESS \\ S100B protein level for the detection of clinically significant intracranial haemorrhage in patients with mild traumatic brain injury: a subanalysis of a prospective cohort study
}

\author{
Julien Blais Lécuyer, ${ }^{1,2}$ Éric Mercier, ${ }^{1,2}$ Pier-Alexandre Tardif, ${ }^{2}$ Patrick M Archambault, ${ }^{3,4}$ \\ Jean-Marc Chauny, ${ }_{1}^{5}$ Simon Berthelot $\left(10,{ }^{2}\right.$ Jérôme Frenette, ${ }^{1}$ Jeff Perry, ${ }^{1,6}$ lan Stiell, ${ }^{6}$ \\ Marcel Émond ${ }^{1,2}$ Jacques Lee, ${ }^{7}$ Eddy Lang, ${ }^{8}$ Andrew McRae $\left(10,{ }^{8}\right.$ Valérie Boucher, ${ }^{2}$ \\ Natalie Le Sage (1) ${ }^{1,2}$
}

Handling editor Jason E Smith

For numbered affiliations see end of article.

\section{Correspondence to}

Dr Natalie Le Sage, Department of Family Medicine and Emergency Medicine, Laval University Faculty of Medicine, Quebec, QC G1J 1Z4, Canada; natalie.lesage@fmed.ulaval.ca

Received 2 March 2020 Revised 21 October 2020 Accepted 8 November 2020

Published Online First

18 December 2020

\section{Check for updates}

(c) Author(s) (or their employer(s)) 2021. Re-use permitted under CC BY-NC. No commercial re-use. See rights and permissions. Published by BMJ.

To cite: Blais Lécuyer J,

Mercier É, Tardif P-A

et al. Emerg Med J

2021:38:285-289.

\section{ABSTRACT}

Background Clinical assessment of patients with mild traumatic brain injury (mTBI) is challenging and overuse of head CT in the ED is a major problem. Several studies have attempted to reduce unnecessary head CTs following a mTBI by identifying new tools aiming to predict intracranial bleeding. Higher levels of S100B protein have been associated with intracranial haemorrhage following a $\mathrm{mTBI}$ in previous literature. The main objective of this study is to assess whether plasma S100B protein level is associated with clinically significant brain injury and could be used to reduce the number of head CT post-mTBI.

Methods Study design: secondary analysis of a prospective multicentre cohort study conducted between 2013 and 2016 in five Canadian EDs. Inclusion criteria: non-hospitalised patients with mTBI with a GCS score of 13-15 in the ED and a blood sample drawn within 24 hours after the injury. Data collected: sociodemographic and clinical data were collected in the ED. S100B protein was analysed using ELISA. All CT scans were reviewed by a radiologist blinded to the biomarker results. Main outcome: the presence of clinically important brain injury.

Results 476 patients were included. Mean age was $41 \pm 18$ years old and $150(31.5 \%)$ were women. Twenty-four (5.0\%) patients had a clinically significant intracranial haemorrhage. Thirteen patients (2.7\%) presented a non-clinically significant brain injury. A total of $37(7.8 \%)$ brain injured patients were included in our study. S100B median value (Q1-Q3) was: $0.043 \mu \mathrm{g} / \mathrm{L}$ (0.008-0.080) for patients with clinically important brain injury versus $0.039 \mu \mathrm{g} / \mathrm{L}(0.023-0.059)$ for patients without clinically important brain injury. Sensitivity and specificity of the S100B protein level, if used alone to detect clinically important brain injury, were $16.7 \%$ (95\% Cl $4.7 \%$ to $37.4 \%)$ and $88.5 \%$ (95\% Cl $85.2 \%$ to $91.3 \%)$, respectively.

Conclusion Plasma S100B protein level was not associated with clinically significant intracranial lesion in patients with $\mathrm{mTBI}$.

\section{INTRODUCTION}

Mild traumatic brain injury (mTBI) is a major public health problem. The annual incidence of mTBI has

\section{What is already known on this subject}

- Clinical assessment of patients with a mild traumatic brain injury (mTBI) is challenging and overuse of head CT in the ED is a major problem. Studies have investigated the sensitivity of the S100B protein in the early detection of intracranial lesions on head CT. However, most studies have used S100B protein in heterogeneous populations with head trauma, without according importance on clinically important brain injury.

\section{What this study adds}

- The plasma S100B protein level showed a poor association with clinically important brain injury in the first 24 hours after a mTBI. It would not have been useful in reducing the number of head CT performed in the ED in a well-defined non-hospitalised population with mTBI.

been estimated to be 600 per 100000 population worldwide. MTBI is defined by most experts as a head injury associated with loss of consciousness and/or amnesia and/or disorientation with a GCS score of $13-15 .{ }^{1}$ It is the most common form of traumatic brain injury (TBI) and represents 70\%-90\% of all TBI. Approximately $10 \%$ of patients will have an intracranial injury detected on CT following an mTBI but less than $1 \%$ will actually require a neurosurgical intervention. ${ }^{23}$ Intracranial injuries should be promptly identified, as their consequences can be catastrophic for those requiring a neurosurgical intervention. $^{12}$

Clinical assessment of patients with $\mathrm{mTBI}$ is challenging and overuse of head CT in the ED is a major problem. Even with the Canadian CT head rule (CCHR), a validated and widely used tool, up to $30 \%$ of patients with mTBI without an indication to perform a head CT have one while in the ED. ${ }^{4}$ During the last decades, studies aiming to identify new intracranial bleeding prediction tools 
were conducted in an attempt to reduce unnecessary head CTs following a mTBI. ${ }^{5-10}$ Some authors tested the use of neurobiochemical markers to refine current models to detect intracranial haemorrhages and better predict the evolution of these injuries. ${ }^{11} 12$ S100B protein is one of the most studied biomarkers to evaluate of traumatic brain haemorrhage and its consequences. ${ }^{1314}$ A higher level of $\mathrm{S} 100 \mathrm{~B}$ protein has been associated with intracranial haemorrhage following a mTBI as this protein is released by the injured cells within seconds of impact. ${ }^{15}$ Increased levels of S100B protein in plasma may indicate a dysfunction of the blood-brain barrier and hence a potential injury. ${ }^{511}$ Some studies have investigated the sensitivity of the S100B protein in the early detection of intracranial lesions on head CT and their results have been promising. ${ }^{8} 1617$

Although S100B protein is considered a sensitive marker for the detection of $\mathrm{mTBI},{ }^{816}$ its usefulness in reducing the number of unnecessary head CTs in patients with mTBI should be further studied. ${ }^{1}$ The primary objective of this study was therefore to assess the diagnostic value of the plasma S100B protein level drawn within 24 hours of an mTBI to detect the presence of clinically significant intracranial haemorrhage. The secondary objective was to evaluate the diagnostic value of the plasma S100B protein level to detect the presence of all intracranial haemorrhages in adults following a mTBI.

\section{METHODS}

\section{Study setting and population}

This is a secondary analysis of a larger multicentre prospective cohort study conducted in five Canadian hospitals (CHU de Québec-Université Laval (Hôpital de l'Enfant-Jésus); CHAU Hôtel-Dieu de Lévis du CISSS de Chaudière-Appalaches, Lévis; CHAU régional du CIUSSS de la Mauricie, Trois-Rivières; Hôpital du Sacré-Cœur-de-Montréal, Montréal; The Ottawa Hospital, Ottawa) between July 2013 and July 2016.

Patients aged 16 years and over were included if they consulted to a participating ED within 24 hours of a mTBI and had S100B protein blood sampled within 24 hours after the injury. ${ }^{2}$ As per the WHO, mTBI was defined in this study as a head trauma patient with a GCS score of $13-15$ in the ED and one of the following: loss of consciousness $<30 \mathrm{~min}$, confusion, disorientation, amnesia of the event, retrograde amnesia, post-traumatic amnesia $<24$ hours, post-traumatic convulsions or other transient neurological symptoms (loss of vision, diplopia, ataxia, dysarthria, paresthesia or dizziness). Patients who were hospitalised following the ED visit were excluded.

\section{Patient and public involvement}

Patients or the public were not involved in the design, or conduct, or reporting, or dissemination plans of our research.

\section{Data collection}

ED physicians or research nurses collected the data using a standardised questionnaire. Head CT was obtained at the discretion of the attending physician and was thus not performed in every patient.

Research nurses conducted a structured telephone interview at 3 months post-ED visit, in which they collected information regarding the accident, injuries, medical treatment and symptoms. Patients' medical records were also assessed at 3 months in order to make sure participants did not undergo neurosurgery following a clinically significant intracranial haemorrhage.

\section{Blood sampling}

After obtaining informed consent of eligible patients, blood samples were collected by ED nurses within 24 hours from head trauma, and were immediately sent to local laboratories to be centrifuged at $1300 \mathrm{~g}$ relative centrifugal field for $10 \mathrm{~min}$ at $22^{\circ} \mathrm{C}$ or less. Following centrifugation, the collected plasma was frozen at $-20^{\circ} \mathrm{C}$ for a maximum of 2 weeks. Samples were then sent to the Centre Hospitalier de l'Université Laval Central Research Laboratory to be frozen at $-80^{\circ} \mathrm{C}$. Each tube was denominalised to ensure confidentiality. S100B protein levels were measured using Human Protein ELISA kits from Millipore Sigma (Germany) for plasma samples, as per the manufacturer's protocols. The detection limit of the assay used was $0.0027 \mu \mathrm{g} / \mathrm{L}$. Detection of a clinically significant intracranial brain lesion occurs when a $S 100 \beta$ protein level is $\geq 0.10 \mu \mathrm{g} / \mathrm{L}{ }^{56}$

\section{Outcome}

The primary outcome was the presence of any clinically significant intracranial lesion, which was determined using the ED head CT scan. Patients who did not have an initial head CT during the medical assessment and who were not hospitalised within 3-month post-injury, were assumed to be free of any clinically significant intracranial haemorrhage. Head CT scans were interpreted in each participating centre by the attending radiologist who was blinded to the plasma S100B protein level. Clinical significance of intracranial traumatic lesions discovered on head CT was then interpreted by two independent reviewers (trained emergency physicians) according to the clinical significance criteria proposed by Stiell et al. ${ }^{1}$ Patients with clinically insignificant lesions were neurologically intact and had the following CT findings: (1) single contusion of $<5 \mathrm{~mm}$ in diameter, (2) localised subarachnoid blood $<1 \mathrm{~mm}$, (3) subdural haematoma $<4 \mathrm{~mm}$ or (4) closed depressed skull fracture not through the inner table. If the measurement of a lesion was not specified, or if a patient had multiple non-clinically significant lesions, the traumatic anomaly was classified as non-clinically significant. All other traumatic brain injuries were considered clinically significant.

\section{Statistical analysis}

Descriptive analyses are presented with proportions or medians with their corresponding measure of dispersion. The association between plasma S100B protein and the presence of intracranial lesions was assessed using a Wilcoxon rank test. We calculated sensitivity, specificity, positive and negative predictive values with exact binomial 95\% CIs to detect the presence of a clinically significant intracranial lesion when the plasma S100B protein level was $\geq 0.10 \mu \mathrm{g} / \mathrm{L} .^{56}$

$\mathrm{S} 100 \mathrm{~B}$ protein values had a right-skewed distribution and were therefore described using medians. The result was $7.8 \%$ patients had S100B protein values below the limit of detection $(2.7 \mathrm{pg} /$ $\mathrm{mL}$ or $0.0027 \mu \mathrm{g} / \mathrm{L}$ ) and were given a concentration equal to half the limit of detection based on recommendations from the Environmental Protection Agency. ${ }^{18}$

Considering variables that might affect the S100B diagnostic accuracy, we performed predetermined subgroup analyses: gender (male vs female), age ( $<65 \mathrm{vs} \geq 65$ years old), nature of injury (isolated mTBI (defined as non-concomitant injuries identified during the physical examination) vs patients with at least one concomitant injury), and delay between trauma and plasma sampling ( $\leq 3$ hours and $\leq 6$ hours). We restricted analyses to patients with complete data on plasma S100B protein concentrations. We conducted statistical analyses using Statistical Analysis System V.9.4. Statistical significance was set at 0.05 (two-sided tests) for all analyses. 


\section{RESULTS}

A total of 476 patients were included in this study, most of whom were aged under 65 years $(88.4 \%)$ and were men $(68.5 \%)$ (table 1). GCS on arrival was 15 in most patients (85.7\%). A total of $172(39.5 \%)$ patients had isolated mTBI while the presence of at least one fracture was noted in $86(18.1 \%)$ patients.

Twenty-four patients $(5.0 \%)$ had a clinically significant intracranial lesion. Thirteen patients (2.7\%) presented a non-clinically significant intracranial lesion. A total of $37(7.8 \%)$ brain injured patients were included in our study. The mean delay (SD) between the time of the trauma and the blood sampling was 8.5 (10.5) hours.

At the 3-month follow-up, 112 (23,5\%) patients were lost to follow-up, but only $40(8.4 \%)$ of those did not have an initial head CT.

\section{Association between plasma S100B protein level and intracranial haemorrhage}

The median values (IQR) of the plasma S100B protein levels were: $0.0394(0.0231-0.0605)$ for all patients, $0.043 \mu \mathrm{g} / \mathrm{L}$ $(0.008-0.080)$ for patients with clinically significant intracranial lesion and $0.039 \mu \mathrm{g} / \mathrm{L}(0.023-0.059)$ for patients without clinically intracranial lesion. Plasma S100B protein level was not associated with either clinically significant intracranial haemorrhage $(p=0.40)$ alone or all intracranial haemorrhages $(p=0.39)$.

The plasma S100B protein level and intracranial findings of patients with intracranial haemorrhage are presented in table 2. Sensitivity and specificity of the plasma S100B protein level were, respectively, $18.2 \%$ and $88.5 \%(n=476)$ to

\begin{tabular}{lc}
\hline Table $1 \quad$ Characteristics of included patients & \\
\hline All patients ( $\mathrm{n}=476$ ) & \\
\hline Age, mean (SD) & \\
$\quad \geq 65$ years old & $55(11.6)$ \\
\hline Sex (male) & $326(68.5)$ \\
\hline GCS on arrival & \\
\hline 15 & $408(85.7)$ \\
\hline 14 & $63(13.2)$ \\
\hline 13 & $5(1.1)$ \\
\hline Mechanism of injury & \\
\hline Pedestrian struck by motor vehicle & $19(4.3)$ \\
\hline Fall from height $>1$ feet or five stairs & $73(16.6)$ \\
\hline Occupant ejected from motor vehicle & $19(4.3)$ \\
\hline Other & $328(74.7)$ \\
\hline Isolated mTBI & $172(39.5)$ \\
\hline Fractures & $86(18.1)$ \\
\hline Head CT performed & $316(66.4)$ \\
\hline Retrograde amnesia & $127(27.0)$ \\
\hline Anterograde amnesia & $237(51.8)$ \\
\hline Loss of consciousness & $233(49.3)$ \\
\hline Confusion & $266(58.2)$ \\
\hline Vomiting $\geq 2$ episodes & $30(6.3)$ \\
\hline Transient neurological symptoms & $68(14.3)$ \\
\hline Seizures & $15(3.2)$ \\
\hline Anticoagulant and coagulopathy & $12(2.5)$ \\
\hline Suspected open or depressed skull fracture & $7(1.5)$ \\
\hline Any sign of basal skull fracture & $9(1.9)$ \\
\hline Suspected or proven alcohol intoxication & $50(10.5)$ \\
\hline
\end{tabular}

mTBI, mild traumatic brain injury.

\begin{tabular}{|c|c|c|c|c|}
\hline ID & Age & S100B & Cerebral lesions & Outcome \\
\hline 1 & 59 & 0.016 & EH & CS \\
\hline 2 & 64 & 0.185 & SAH-S & CS \\
\hline 3 & 71 & 0.003 & SAH-S & CS \\
\hline 4 & 43 & 0.129 & SAH-S & CS \\
\hline 5 & 67 & 0.026 & CC-S, SAH-S, SDH-N & CS \\
\hline 6 & 52 & 0.060 & SDH-S & CS \\
\hline 7 & 47 & 0.047 & CC-S, SK-N & CS \\
\hline 8 & 34 & 0.001 & SAH-S & CS \\
\hline 9 & 42 & 0.004 & SAH-S, P-N & CS \\
\hline 10 & 58 & 0.001 & CC-S, SAH-S, SDH-S & CS \\
\hline 11 & 63 & 0.092 & EH, SAH-S, SDH-N, SK-N, SDH-N & CS \\
\hline 12 & 39 & 0.060 & SDH-S & CS \\
\hline 13 & 57 & 0.094 & SDH-S & CS \\
\hline 14 & 76 & 0.061 & CC-S, SAH-S & CS \\
\hline 15 & 53 & 0.042 & CC-S, CC-S, SK-N & CS \\
\hline 16 & 23 & 0.001 & $\mathrm{CO}, \mathrm{CC}-\mathrm{M}$ & CS \\
\hline 17 & 43 & 0.147 & $\mathrm{CO}$ & CS \\
\hline 18 & 60 & 0.044 & SAH-S & CS \\
\hline 19 & 61 & 0.039 & EH, SDH-N & CS \\
\hline 20 & 67 & 0.001 & SAH-S & CS \\
\hline 21 & 19 & 0.018 & CO, CC-S, SDH-N, CC-N & CS \\
\hline 22 & 32 & 0.068 & SAH-S, SK-N, CC-M & CS \\
\hline 23 & 25 & 0.012 & EH & CS \\
\hline 24 & 67 & 0.264 & SAH-S & CS \\
\hline 25 & 22 & 0.222 & SDH-N, SDH-N & MNCS \\
\hline 26 & 16 & 0.030 & CC-N, CC-N & MNCS \\
\hline 27 & 75 & 0.044 & SDH-N, SAH-M & MNCS \\
\hline 28 & 51 & 0.052 & CC-M, SAH-S & MNCS \\
\hline 29 & 70 & 0.091 & CC-N, CC-N & MNCS \\
\hline 30 & 22 & 0.001 & SK-N & NCS \\
\hline 31 & 56 & 0.005 & SDH-N & NCS \\
\hline 32 & 53 & 0.019 & CC-N & NCS \\
\hline 33 & 65 & 0.014 & CC-N & NCS \\
\hline 34 & 55 & 0.012 & SAH-M & NCS \\
\hline 35 & 52 & 0.046 & SDH-M & NCS \\
\hline 36 & 16 & 0.043 & SK-N & NCS \\
\hline 37 & 53 & 0.044 & CC-N & NCS \\
\hline
\end{tabular}

CC-M, cerebral contusion missing size; CC-N, cerebral contusion not significant; CC-S, cerebral contusion significant; CO, cerebral oedema; CS, clinically significant; EH, epidural haematoma; MNCS, multiple non-clinically significant; NCS, nonclinically significant; $\mathrm{P}-\mathrm{N}$, isolated pneumocephalus; SAH-M, subarachnoid haemorrhage missing size; SAH-S, subarachnoid haemorrhage significant; SDH-M, subdural haematoma missing size; $\mathrm{SDH}-\mathrm{N}$, subdural haematoma not significant; SDH-S, subdural haematoma significant; SK-N, skull fracture without inner table involvement.

predict clinically significant bleeding while they were $17.7 \%$ and $88.5 \%(\mathrm{n}=476)$ to predict any intracranial haemorrhage (table 3).

In patients with isolated $\mathrm{mTBI}$, sensitivity and specificity were $25.0 \%$ and $89.6 \%(\mathrm{n}=172)$, respectively. A $66.7 \%$ sensitivity and 93.7\% specificity were found in patients with isolated $\mathrm{mTBI}$ and a sampling taken within 6 hours after trauma for the detection of brain injury $(\mathrm{n}=114)$. Age and sex did not influence the association between $\mathrm{S} 100 \mathrm{~B}$ protein level and intracranial haemorrhage. Using the traditional threshold of $\geq 0.10 \mu \mathrm{g} / \mathrm{L}$ to perform a head CT, only 4 of the $24(16.7 \%)$ clinically significant intracranial haemorrhage would have been identified. 


\begin{tabular}{|c|c|c|}
\hline & Clinically significant ICH & Any ICH \\
\hline \multicolumn{3}{|l|}{$\begin{array}{l}\text { Blood sampling } \\
\text { within } 6 \text { hours in } \\
\text { all patients }\end{array}$} \\
\hline Sensitivity, \% & $18.2(95 \% \mathrm{Cl}: 2.3$ to 51.8$)$ & 17.7 (95\% Cl: 3.8 to 43.4$)$ \\
\hline Specificity, \% & 88.5 (95\% Cl: 84.2 to 91.7$)$ & 88.5 (95\% Cl: 84.3 to 91.8$)$ \\
\hline NPV, $\%$ & 96.8 (95\% Cl: 94.0 to 98.5$)$ & 95.0 (95\% Cl: 91.8 to 97.3$)$ \\
\hline PPV, \% & 5.3 (95\% Cl: 0.6 to 17.8$)$ & 7.9 (95\% Cl: 1.7 to 21.4$)$ \\
\hline Patients, n & 320 & 320 \\
\hline \multicolumn{3}{|l|}{$\begin{array}{l}\text { Blood sampling } \\
\text { within } 24 \text { hours in } \\
\text { all patients }\end{array}$} \\
\hline Sensitivity, \% & $16.7(95 \% \mathrm{Cl}: 4.7$ to 37.4$)$ & 13.5 (95\% Cl: 4.5 to 28.8$)$ \\
\hline Specificity, \% & 88.5 (95\% Cl: 85.2 to 91.3$)$ & 88.4 (95\% Cl: 85.0 to 91.2$)$ \\
\hline NPV, $\%$ & 95.2 (95\% Cl: 92.7 to 97.1$)$ & 93.4 (95\% Cl: 89.4 to 94.7$)$ \\
\hline PPV, $\%$ & 7.1 (95\% Cl: 1.9 to 17.3$)$ & 8.9 (95\% Cl: 2.9 to 19.6$)$ \\
\hline Patients, n & 476 & 476 \\
\hline \multicolumn{3}{|l|}{$\begin{array}{l}\text { Blood sampling } \\
\text { within } 6 \text { hours in } \\
\text { isolated mTBI }\end{array}$} \\
\hline Sensitivity, \% & 66.7 (95\% Cl: 9.4 to 99.2$)$ & 66.7 (95\% Cl: 9.4 to 99.2$)$ \\
\hline Specificity, \% & 93.7 (95\% Cl: 87.4 to 97.4$)$ & 93.7 (95\% Cl: 87.4 to 97.4$)$ \\
\hline$N P V, \%$ & 99.1 (95\% Cl: 94.8 to 99.9$)$ & 99.1 (95\% Cl: 94.8 to 99.9$)$ \\
\hline PPV, \% & 22.2 (95\% Cl: 2.8 to 60.0$)$ & $22.2(95 \% \mathrm{Cl}: 2.8$ to 60.0$)$ \\
\hline Patients, n & 114 & 114 \\
\hline \multicolumn{3}{|l|}{$\begin{array}{l}\text { Blood sampling } \\
\text { within } 24 \text { hours in } \\
\text { isolated mTBI }\end{array}$} \\
\hline Sensitivity, \% & $25.0(95 \%$ Cl: 3.2 to 65.1$)$ & 22.2 (95\% Cl: 2.8 to 60.0$)$ \\
\hline Specificity, \% & 89.6 (95\% Cl: 83.9 to 93.8$)$ & 89.6 (95\% Cl: 83.8 to 93.8$)$ \\
\hline NPV, \% & 96.1 (95\% Cl: 91.7 to 98.6$)$ & 95.4 (95\% Cl: 90.8 to 98.1$)$ \\
\hline PPV, \% & $10.5(95 \% \mathrm{Cl}: 1.3$ to 33.1$)$ & 10.5 (95\% Cl: 1.3 to 33.1$)$ \\
\hline Patients, n & 172 & 172 \\
\hline
\end{tabular}

mTBI, mild traumatic brain injury; NPV, negative predictive value; PPV, positive predictive value.

\section{DISCUSSION}

In our cohort of non-hospitalised mTBI patients, the plasma S100B protein level showed a poor association with clinically significant intracranial lesion and would not have been useful in reducing the number of head CT performed in the ED. A plasma S100B concentration of $0.10 \mu \mathrm{g} / \mathrm{L}$ would have missed $83.3 \%$ of clinically important brain injuries.

Several studies published data on diagnostic sensitivity of S100B protein, however most included 'minor head trauma' patients with no clear definition, that do not have indications for a head CT using validated criteria. ${ }^{6}{ }^{16}$ Our study only included patients with a diagnosis of mTBI as per the WHO's definition. ${ }^{13}$

Furthermore, most studies have used S100B protein in heterogeneous populations and for patients with a low risk of intracranial bleeding, including 'minor head injuries' or 'minimal head trauma'. They have included unrepresentative populations with age and comorbidities exclusion criteria and have often used restrictive delays between the head trauma and the blood sampling, which are not generalisable to the ED's mTBI population. $^{14}$

Many studies regarding the S100B protein have focused on the detection of any intracranial lesions. ${ }^{13}$ However, from a clinical perspective, the detection of clinically significant haemorrhage is a more useful outcome. Few studies have used a well-defined set of criteria to identify this type of intracranial lesion, which is why our steering committee has decided to use the significance criteria proposed by the CCHR. ${ }^{1}$ This allows a better definition of our outcome and helps to clarify the value of the S100B protein in this clinical setting.

The delay between the mTBI and the blood sampling could potentially have an impact on the association between intracranial haemorrhage and plasma S100B protein levels as the half-life of the S100B protein is $90-120 \mathrm{~min}$. It is therefore biologically plausible that the detectable concentration of the S100B protein could decrease as time elapses. ${ }^{19}{ }^{20}$ Several studies used a shorter delay of enrolment (3-6 hours following the trauma) to evaluate the diagnostic value of S100B protein for brain haemorrhage, ${ }^{5-10}$ most of which obtained an excellent sensitivity. Our sensitivity of only $16.7 \%$ to detect clinically significant intracranial haemorrhage might limit the usefulness of the $\mathrm{S} 100 \mathrm{~B}$ protein measurement for our 156 (32.8\%) mTBI after 6 hours.

While initial plasma S100B protein levels have been associated with mortality or long-term poor functional outcome following a moderate or severe TBI, other biomarkers could be more specific to detect clinically important brain injury following a mTBI but the literature on that topic is still scant. ${ }^{21}$ Biomarkers such as glial fibrillar acidic protein (GFAP), neuron specific enolase (NSE), ubiquitin c-terminal hydrolase (UCH-L1), neurofilament light chain (NF-L) and C-Tau have all been studied. In a recent metaanalysis, the five biomarkers were compared ${ }^{13}$ and it was shown that $\mathrm{S} 100 \mathrm{~B}$ protein was the most studied biomarker. Nevertheless, very few studies were dedicated to the other biomarkers ${ }^{13}$ A recent study proposes a multiplex test which includes four biomarkers: GFAP, UCH-L1, NF-L and C-Tau. The combination of the four biomarkers could offer more information to identify intracranial haemorrhage. ${ }^{22}$

\section{Limitations}

This study has limitations. We used a convenience sample of secondary data initially dedicated to assessing head CT scan in patients who were not hospitalised. It is therefore impossible to use our data to assess the ability to predict the need for neurosurgery because none of our patients underwent neurosurgery. Nonetheless, several recruiting hospitals observed patients with clinically significant intracranial haemorrhage for up to 24 hours without admitting them and these cases were captured within our cohort. Indeed, when they had intracranial haemorrhage, some proportion of our study participants were observed in the ED under the care of a neurosurgeon, for up to 48 hours after trauma. This could create an ascertainment bias, but this practice is representative of the current management in some EDs across Canada. ${ }^{23} 24$

\section{CONCLUSION}

Following an mTBI, plasma S100B protein level was not associated with clinically significant intracranial haemorrhage and would have missed many clinically important brain injuries in non-hospitalised patients. Future research should focus on different ways to assess patients with a mTBI and ultimately reduce unnecessary head $\mathrm{CT}$.

'Department of Family Medicine and Emergency Medicine, Université Laval, Quebec, Quebec, Canada

${ }^{2}$ Axe de recherche en Santé des populations et pratiques optimales en santé, CHU de Quebec-Universite Laval Research Center, Quebec, Quebec, Canada

${ }^{3}$ Department of Anesthesiology and Critical Care Medicine, Université Laval, Quebec, Quebec, Canada
} 
${ }^{4}$ Chaudiere-Appalaches Integrated Health and Social Services Center, Lévis, Quebec, Canada

${ }^{5}$ Department of family medicine and emergency medicine, University of Montreal, Montreal, Quebec, Canada

${ }^{6}$ Department of emergency medicine, Ottawa Hospital Research Institute, Ottawa, Ontario, Canada

${ }^{7}$ Schwartz/Reisman Emergency Medicine Institute, Toronto, Ontario, Canada

${ }^{8}$ Department of emergency medicine, University of Calgary, Calgary, Alberta, Canada

Twitter Simon Berthelot @simon_berthelot and Andrew McRae @Andrew_McRae_ EM

Acknowledgements We are deeply indebted to all the patients who participated in this study and gratefully acknowledge the emergency physicians at the study sites who recruited the patients and the emergency medicine residents who helped in this process. We acknowledge the following members of our research team: Quebec site-Marilyne Dufresne, Martin Roy, Catherine Bédard and Suzy Lavoie; Lévis siteLise Lavoie and Josée Jolicoeur; Trois-Rivières site-Émilie Gouin and Annie Cossette; Montreal site-Chantal Lanthier, Tanya Leduc and Catherine Perreault-Légaré; Ottawa site-Connor Sheehan.

Contributors NLS had full access to all of the study data and takes responsibility for the integrity of the data and the accuracy of the data analysis. NLS, ÉM and JBL were responsible for design and conduct of the study. JBL, ÉM, P-AT and NLS wrote the manuscript and led the statistical analyses and data interpretation. PMA, J-MC, $S B, J F, J P, I S, M E ́, J L, E L, A M$ and VB critically reviewed and approved the manuscript.

Funding Fonds de Recherche du Québec-Santé (\#35334).

Competing interests None declared.

Patient and public involvement Patients and/or the public were not involved in the design, or conduct, or reporting, or dissemination plans of this research.

Patient consent for publication Not required.

Ethics approval The study was approved by the Research Ethics Committee in all of the recruiting hospitals.

Provenance and peer review Not commissioned; externally peer reviewed.

Data availability statement Data are available upon reasonable request. The data that support the findings of this study are available from the corresponding author, Dr Natalie Le Sage, upon reasonable request.

Open access This is an open access article distributed in accordance with the Creative Commons Attribution Non Commercial (CC BY-NC 4.0) license, which permits others to distribute, remix, adapt, build upon this work non-commercially, and license their derivative works on different terms, provided the original work is properly cited, appropriate credit is given, any changes made indicated, and the use is non-commercial. See: http://creativecommons.org/licenses/by-nc/4.0/.

\section{ORCID iDs}

Simon Berthelot http://orcid.org/0000-0002-0372-0586

Andrew McRae http://orcid.org/0000-0003-2743-4290

Natalie Le Sage http://orcid.org/0000-0003-4762-8156

\section{REFERENCES}

1 Stiell IG, Wells GA, Vandemheen K, et al. The Canadian CT head rule for patients with minor head injury. Lancet 2001;357:1391-6.

2 af Geijerstam J-L, Britton M. Mild head injury - mortality and complication rate: meta-analysis of findings in a systematic literature review. Acta Neurochir 2003:145:843-50.

3 Smits M, Dippel DWJ, de Haan GG, et al. External validation of the Canadian CT head rule and the new Orleans criteria for CT scanning in patients with minor head injury. JAMA 2005;294:1519-25.
4 Melnick ER, Szlezak CM, Bentley SK, et al. Ct overuse for mild traumatic brain injury. It Comm I Qual Patient Saf 2012:38:483-9.

5 Heidari K, Vafaee A, Rastekenari AM, et al. S100B protein as a screening tool for computed tomography findings after mild traumatic brain injury: systematic review and meta-analysis. Brain Inj 2015;29:1146-57.

6 Biberthaler P, Linsenmeier U, Pfeifer K-J, et al. Serum S-100b concentration provides additional information fot the indication of computed tomography in patients after minor head injury: a prospective multicenter study. Shock 2006;25:446-53.

7 Laribi S, Kansao J, Borderie D, et al. S100B blood level measurement to exclude cerebral lesions after minor head injury: the multicenter STIC-S100 French study. Clin Chem Lab Med 2014;52:527-36.

8 Zongo D, Ribéreau-Gayon R, Masson F, et al. S100-B protein as a screening tool for the early assessment of minor head injury. Ann Emerg Med 2012;59:209-18.

9 Egea-Guerrero JJ, Revuelto-Rey J, Murillo-Cabezas F, et al. Accuracy of the $\mathrm{S} 100 \beta$ protein as a marker of brain damage in traumatic brain injury. Brain Inj 2012;26:76-82.

10 Bazarian JJ, Blyth BJ, He H, et al. Classification accuracy of serum apo A-I and S100B for the diagnosis of mild traumatic brain injury and prediction of abnormal initial head computed tomography scan. J Neurotrauma 2013;30:1747-54.

11 Herrmann M, Jost S, Kutz S, et al. Temporal profile of release of neurobiochemical markers of brain damage after traumatic brain injury is associated with intracranial pathology as demonstrated in cranial computerized tomography. J Neurotrauma 2000;17:113-22.

12 Undén L, Calcagnile 0 , Undén J, et al. Validation of the Scandinavian guidelines for initial management of minimal, mild and moderate traumatic brain injury in adults. BMC Med 2015;13:292

13 Mondello S, Sorinola A, Czeiter E, et al. Blood-Based protein biomarkers for the management of traumatic brain injuries in adults presenting to emergency departments with mild brain injury: a living systematic review and meta-analysis. J Neurotrauma 2018. doi:10.1089/neu.2017.5182. [Epub ahead of print: 02 Jul 2018].

14 Mercier E, Tardif P-A, Emond M, et al. Characteristics of patients included and enrolled in studies on the prognostic value of serum biomarkers for prediction of postconcussion symptoms following a mild traumatic brain injury: a systematic review. BMJ Open 2017;7:e017848.

15 Thelin EP, Nelson DW, Bellander B-M. A review of the clinical utility of serum S100B protein levels in the assessment of traumatic brain injury. Acta Neurochir 2017;159:209-25.

16 Allouchery G, Moustafa F, Roubin J, et al. Clinical validation of S100B in the management of a mild traumatic brain injury: issues from an interventional cohort of 1449 adult patients. Clin Chem Lab Med 2018;56:1897-904.

17 Undén J, Romner B. Can low serum levels of S100B predict normal CT findings after minor head injury in adults?: an evidence-based review and meta-analysis. J Head Trauma Rehabil 2010;25:228-40.

18 EPA US. Guidance for data quality assessment: practical methods for data analysis EPA QA/G-9 QUW. DC: US: Environmental Protection Agency, 2000

19 Townend W, Dibble C, Abid K, et al. Rapid elimination of protein S-100b from serum after minor head trauma. J Neurotrauma 2006;23:149-55.

20 Kleindienst A, Meissner S, Eyupoglu IY, et al. Dynamics of S100B release into serum and cerebrospinal fluid following acute brain injury. Acta Neurochir Suppl 2010;106:247-50

21 Mercier E, Boutin A, Lauzier F, et al. Predictive value of $\mathrm{S}-100 \beta$ protein for prognosis in patients with moderate and severe traumatic brain injury: systematic review and meta-analysis. BMJ 2013;346:f1757.

22 Korley FK, Yue JK, Wilson DH, et al. Performance evaluation of a multiplex assay for simultaneous detection of four clinically relevant traumatic brain injury biomarkers. Neurotrauma 2018. doi:10.1089/neu.2017.5623. [Epub ahead of print: 23 Jul 2018].

23 Cheng I, Taylor D, Schull MJ, et al. Comparison of emergency department time performance between a Canadian and an Australian academic tertiary hospital. Emergency medicine Australasia: EMA, 2019: 31. 605-11.

24 Aaronson EL, Kim J, Hard GA, et al. Emergency department visits by patients with an internal medicine specialist: understanding the role of specialists in reducing ED crowding. Intern Emerg Med 2019;14:777-82. 